\title{
Poder, assujeitamento, subjetivação
}

Bruno Karsenti

Directeur d'études - L’École des hautes études en sciences sociales- EHESS

Versão do texto originalmente publicado na revista Futur Antérieur, numéro $10: 1992 / 2$, sob o título Pouvoir, assujettissement, subjectivation. Republicado na Entre-là em 14 de março de 2013 e disponível em: http://xn--entre-l-fwa.net/pouvoir-assujettissementsubjectivation-par-bruno-karsenti/ . Último acesso: 01/10/2019.

Tradução: Sandra Raquel Santos de Oliveira, Larissa de Moura Cavalcante e Maria Cândida Santos e Moura. Supervisão: Manoel Carlos Cavalcanti de Mendonça Filho. Desenvolvido como atividade do GEPEC/UFS, coordenado por Marcelo de Almeida Ferreri.

Obs sobre a tradução: ao final das páginas, encontram-se as notas das tradutoras. Ao final do texto, as notas originais do autor, em que as páginas indicadas correspondem às publicações francesas).

DOI: 10.12957/mnemosine.2020.52696

Deve-se reconhecer: sente-se, inevitavelmente, certo estranhamento quando se interroga sobre a relação de Foucault com o marxismo, ou quando se procura dar um significado preciso ao seu "esquerdismo". Não pensamos somente na pluralidade das atitudes a respeito de Marx - ao lado do marxismo "relativizado", identificado em $A s$ Palavras e as Coisas como figura característica da disposição do saber do século XIX, há o Marx sempre presente, com o qual o debate perdura, esse Marx muito diferente daquele da "comunistologia" ${ }^{1}$ " nem no compromisso com formas disparatadas, tão intensas no correr dos anos setenta. De fato, tudo se passa como se o próprio Foucault tivesse disposto sua obra e sua vida estrategicamente, repensando completamente a relação entre a teoria e a prática política, de maneira a impossibilitar as denominações e a contornar

1 Quando questionado sobre a possibilidade de uma espécie de sistematização de um saber (ciência) da revolução (em entrevista intitulada "A morte do pai” para o Libération, em 1975), Michel Foucault afirma existir uma ciência que poderia se chamar de "comunistologia", que seria uma ciência histórica constituída de análises institucionais bastante precisas. Mas, para ele, naquele momento, esta "comunistologia", a partir da qual o marxismo se desenvolveu como ciência, como dogma, ainda lhe escapava. (NT). 
incessantemente o que ele amava chamar de lógica do estado civil, viesse ela na forma de cobrança filosófica.

No que diz respeito à obra, contudo, é comum distinguir geralmente dois períodos e insistir, ao mesmo tempo, sobre o caráter problemático de sua continuidade: em resumo, Foucault teria inicialmente procurado caracterizar - num sentido que, sem ser marxista, não se afasta radicalmente de temáticas essenciais do marxismo - a alienação dos indivíduos, revelando alguns mecanismos de poder a que estamos submetidos como sujeitos sociais. Na sequência, ao fim do que se pôde ler, se não como uma reavaliação, ao menos como uma reviravolta, a reflexão inclinar-se-ia para o estudo dos modos de atividades pelos quais o indivíduo constitui-se e afirma-se como sujeito - práticas de si, tipos específicos e historicamente localizados da relação de si para consigo em que o próprio sujeito identifica-se como sujeito moral, sujeito de desejo e sujeito de prazer. Se dermos ouvidos a um 'comentador', a teoria do biopoder, desenvolvida em $A$ vontade de saber, desapareceria totalmente em favor de uma "reflexão exemplar sobre a organização da existência pessoal" no seio de uma moral pós-convencional"2.

Tendo em vista o desprezo que Foucault reservava àqueles para quem as mudanças de abordagem passam necessariamente por confissões de inconsistência ${ }^{3}$, pode-se dizer que se o problema é de exegese e visa a restaurar a unidade da obra, neste caso, ele é em vão. Mas o desafio é outro: até que ponto o pensamento de Foucault conserva uma pertinência política real? O aparecimento, a partir de $O$ uso dos prazeres, dos temas "estética da existência", "estilização da conduta" ou "técnicas de si" é sinal de um abandono do político em favor de uma reflexão orientada para a ética, ou corresponde a uma nova forma de problematização do político, elaborada - e esta seria sua característica essencial - no nível mesmo das práticas subjetivas?

Entretanto, olhando de perto, parece que uma noção, pelas variações semânticas que admite, é suscetível de assimilar a oposição entre as duas perspectivas acima evocadas, de esclarecer o pensamento político de Foucault inclusive em sua dimensão ética e, por isso mesmo, de dar conta, não da sua unidade doutrinária, mas sobretudo da difícil coerência do seu movimento. Essa noção é a de assujeitamento.

Compreender como um "assujeitamento" os processos complexos de submissão dos indivíduos ao poder não parece, à primeira vista, colocar-se como um problema particular, dada a proximidade dos termos ao ponto de vista estrito do senso comum. 
Contrariamente, as dificuldades emergem quando se trata de compreender a subjugação ${ }^{2}$ como subjetivação, ou seja, como uma certa modalidade da construção de si para consigo do sujeito social. Mais precisamente, a validade da segunda tese não se basearia em uma maior atenção concedida à primeira? Para pensar a sujeição como modo de subjetivação, é, sem dúvida, necessário, antes, esclarecer a concepção de "assujeitamento" como submissão ao poder, restituir a sua originalidade e a flexibilidade de seu sentido - neste caso, pode-se falar em submissão? - e ver em que, longe de barrar toda possibilidade de prática subjetiva e libertadora, ela define condições paradoxais que lhe são próprias e tenta esboçar o espaço estreito em que se constitui. Então, é necessário partir de uma caracterização rigorosa do poder e das relações específicas que ele põe em jogo. Sob essa perspectiva ver-se-á, portanto, que os últimos livros de Foucault - por meio de uma história da sexualidade que é muito mais uma história dos modos de "problematização ética" do que uma história dos sistemas de moralidade, adotando uma perspectiva que parece restringir-se ao nível das práticas individuais - não deixam, no entanto, de ter fortes repercussões políticas e contribuem para colocar a questão da construção das lutas no terreno social em termos novos e fecundos.

$* * *$

Nos textos de Foucault que têm diretamente como objeto a questão do poder, aparece, sob uma forma mais ou menos estabelecida, uma proposição tão evidentemente escandalosa que se tem dificuldade em delimitar a sua ironia: é que, de certa forma, "o poder não existe" ${ }^{\text {. }}$ Poderíamos, de acordo com a tese de Derrida, procurar explicar a coexistência, num mesmo desenvolvimento, da palavra e da sua "rasura": a palavra, ainda legível sob rasura, consegue dizer a sua não-verdade. Tem-se aqui algo de análogo: nisto que pretendia ser não uma teoria geral fadada ao dogmatismo, mas simplesmente uma investigação crítica do poder, é necessário fazer dizer do poder o que ele não é, introduzindo, assim, ao menos a título de pressuposto metodológico, a suspeita da sua inexistência.

“O poder não existe”, entendendo-se por poder uma força essencialmente repressiva, que age de fora, e destinada a barrar uma espécie de energia rebelde cujos

2 Nessa passagem optamos por alternar a palavra "assujeitamento", que se configura como um conceito central do texto, por variações como subjugação e sujeição, para acentuar a passagem de passivo para ativo que a questão coloca. (NT) 
sujeitos, considerados tanto como multiplicidade de singularidades irredutíveis quanto como entidade coletiva unificada, seriam os depositários originais. Isso não quer dizer, porém, que a jurisdição do poder se exerce na realidade de maneira mais sutil, ou mesmo de maneira contraditória. Nós, instruídos em psicanálise, há muito tempo sabemos da pouca pertinência do esquema mecanicista, que só concebe a oposição entre dois termos de maneira externa, sem conseguir pensar sua constituição respectiva. Que a relação trabalhe internamente cada um dos termos, que estes, aqui, sejam solidários inclusive em sua própria contradição, que lei e desejo oponham-se apenas ao se constituir mutuamente, que, consequentemente, a lei ganhe sentido apenas a partir de sua violação, tampouco é isso que Foucault quer dizer. De modo ainda mais radical, o que não existe, ou, ao menos, o que se deve suspeitar não existir, é o poder-lei tomado na integralidade de suas acepções, quer admitam ou não uma complementaridade da interdição e de sua transgressão, quer inscrevam a lei no coração mesmo do desejo ou coloquem sua separação como primeira.

Qualquer que seja o caso, a concepção jurídica faz do poder um elemento ao mesmo tempo restritivo e uniforme - e isso em qualquer que seja o nível no qual se pretenda fazê-lo operar. Em nome disto, ela esvazia a realidade das relações de poder de duas maneiras: por um lado, por não dar conta daquilo que poderia constituir o caráter positivo ou produtivo do poder; por outro, por não considerar a especificidade de cada uma das formulações do poder, a sua capacidade de se atualizar constantemente em função de processos inéditos, determinados pelas condições particulares do seu plano de intervenção. Ora, precisamente, à concepção tradicional de um poder unificado, massivo e impositivo como pode ser um sistema de leis - o poder sentencioso, que somente teria a virtude do "não" -, Foucault contrapõe, por meio de uma série de análises locais, o esboço de um poder sem dúvida mais inquietante ainda: poder inventivo e móvel, tão eficaz quanto essencialmente heterogêneo. Poder plenamente positivo que, no próprio processo de sua lógica interna, vai necessariamente até mesmo afirmar seu "outro", não simplesmente para lhe dar permissão - o que introduziria apenas uma exceção no regime de interdição -, mas, ao contrário, para se servir disso no âmbito de uma estratégia determinada e para constituí-lo como ponto de apoio na sua efetuação.

As páginas de Vigiar e Punir dedicadas ao surgimento, no século XIX, da categoria da delinquência são muito significativas para esse tema. Elas mostram que a lei, longe de se opor aos ilegalismos, nada mais é do que uma gestão específica de suas relações ${ }^{6}$. Diferenciando os ilegalismos, fazendo-os operar juntos e com uma lógica 
particular, opondo-os entre eles ou combinando-os, a lei desenha um tipo de configuração global de relações de força que ela leva a um certo nível de estabilidade, sem jamais anulá-las. A partir daí, reverte-se a imagem tradicional da lei como uma força restritiva, para conceber sua solidariedade com suas múltiplas violações de maneira absolutamente positiva: as violações não são apenas constitutivas da lei, mas subsistem em seu seio como violações e, enquanto tais, conferem à lei toda a sua consistência. A imanência é, então, perfeitamente rigorosa: em nenhum momento um procedimento de conversão ou de negação do que é feito é requerido para confirmar a efetividade do poder, já que são os próprios ilegalismos os verdadeiros agentes do processo, tecendo entre eles a trama da sua própria regulação.

Essa concepção original do poder, oposta à concepção negativa influenciada pelo modelo jurídico, é retomada e intensificada no primeiro volume da História da sexualidade. Contra a hipótese segundo a qual o século XVII marcaria, no Ocidente, o início de uma repressão crescente ao sexo, repressão da qual a sociedade burguesa do século XIX constituiria o lastro histórico mais efetivo, $A$ vontade de saber descreve um jogo curioso e constantemente reiterado, em que se vê que os pontos de contato entre prazer e poder não se deixam conduzir pela lógica da confrontação ou da contradição: "prazer e poder não se anulam, não se opõem um ao outro, complementam-se, sobrepõemse e renovam-se. Estão ligados por mecanismos complexos de excitação e de incitação"7.

A coexistência e a combinação, no decorrer do século XIX, de uma multiplicação das perversões e de um rigor crescente das interdições mostram suficientemente que a problemática do assujeitamento, concernente à experiência ligada ao sexo, não pode ser adequadamente posta em termos de lei e de desejo. E uma vez que a efetividade do poder consiste menos na capacidade inequívoca de censurar do que na capacidade, ao mesmo tempo positiva e diferenciada, de produzir forças, de ordená-las, de organizar suas relações, de arranjar, segundo uma estratégia determinada, seu co-pertencimento a um dispositivo único, é, então, bem menos a partir do modelo jurídico do que do modelo econômico que uma verdadeira análise se mostra possível. A suspeita inicial encontraria, então, seu diagnóstico: se o poder parece escapar-nos em sua realidade concreta e múltipla, é porque ainda nos falta constantemente uma certa economia a partir da qual ele se tornaria apreensível na diversidade dos seus procedimentos; aquém da questão clássica de sua legitimidade, o estudo empírico de suas lógicas variadas, de sua composição 
dinâmica, da distribuição das forças que o atravessam por toda parte, e que, em última análise, consubstanciam-no como efeito global de regulação.

Ora, minar os fundamentos da modelização jurídica do poder restritivo significa, na prática, formular a problemática do assujeitamento dos indivíduos em termos bastante novos. No âmbito do poder-lei, o posicionamento do sujeito se deixa caracterizar de forma clara: "diante de um poder que é lei, o sujeito que se constitui como sujeito - que é 'subjugado' ${ }^{3}$ - é aquele que obedece. A homogeneidade formal do poder, no decorrer de suas instâncias, corresponderia, para aquele que ele coage - quer se trate do sujeito diante do monarca, do cidadão diante do Estado, da criança diante dos pais, do discípulo diante do mestre -, à forma geral da submissão. Poder legislador de um lado e sujeito obediente do outro" 8 . Em contrapartida, em uma concepção efetivamente positiva do poder, a atividade própria do sujeito torna-se parte interessada do processo pelo qual ele é posto como um sujeito. É claro que o assujeitamento não pode ser resolvido sob a forma geral da submissão.

Com efeito, uma tal forma subentende sempre, em um ou outro nível, uma flexão do sujeito, a negação dele mesmo no domínio fixado pela obediência a uma autoridade autoridade que, exterior ou integrada, garante sua hegemonia sob o modo mais ou menos sutil da imposição. Ora, a astúcia suprema do poder, na realidade, é que ele sequer precisa empregar sua astúcia, precisamente porque não se impõe. Na perspectiva de Foucault, o assujeitamento do indivíduo só é concebível na medida em que diz respeito a sujeitos livres, sujeitos que agem e, ao agir, fazem efetivamente uso da sua liberdade. O poder pode muito bem associar-se à violência e à lei; ele não é nem uma coisa nem outra, considerado na sua própria natureza. No princípio do seu exercício está posta a existência de um sujeito livre, fonte de eventuais ações, de invenções, de novas situações que definem um campo aberto de possibilidades - possibilidades que o poder se encarrega precisamente de estruturar no próprio movimento de sua produção. Esta estruturação não é, então, nem a priori nem a posteriori; nem da ordem do domínio jurídico, previamente fixado, nem da violência repressiva vinda après-coup, mas exatamente contemporânea ao desenvolvimento das subjetividades. Ela se inventa no próprio seio do

3 No texto original encontra-se a palavra 'assujetti', que comporta seu primeiro significado como adjetivo utilizado aqui: 'submetido'. Este termo também pode ser encontrado como sujeito passivo, fixado, seguro e também corresponde ao modo como os franceses referem-se a "contribuinte". Em português, podemos igualmente concebê-lo como assujeitado ou subjugado. (NT). 
desenvolvimento das forças e de suas relações, colocando tanto melhor seu objeto quanto mais dele produz suas próprias condições de exercício.

Em suma, o poder não constrange: ele conduz, controla, "probabiliza"4 uma multiplicidade de ações que não forma jamais uma totalidade fechada. Ele governa, é da ordem do governo: "É necessário conferir a esta palavra o significado mais amplo que ela tinha no século XVI. Ela não se referia apenas às estruturas políticas e à gestão dos Estados; mas designava a maneira de dirigir a conduta de indivíduos ou de grupos: governo das crianças, das almas, das comunidades, das famílias, dos doentes. Governar, nesse sentido, é estruturar o possível campo de ação dos outros" ${ }^{\prime 9}$.

Caracterizar o poder em termos de governo é o mesmo que ancorar o questionamento político num questionamento ético. Isso não significa, porém, que o poder se difunda até se insinuar nos detalhes os mais ínfimos da conduta individual. Governar é agir não sobre o real, mas sobre o possível. As práticas subjetivas não são, então, nessa perspectiva, dissolvidas por uma rede mais ou menos complexa e fina de determinações objetivas. Ao contrário, não somente elas são mantidas e ativadas, mas é de fato a partir delas que os processos de assujeitamento tornam-se inteligíveis em sua plena efetividade. A importância primordial conferida ao plano ético, mais que isso, a "reviravolta" ética da obra de Foucault encontra aqui uma explicação no próprio domínio da investigação crítica do poder desencadeada desde o seu começo. É que a conduta dos sujeitos, a maneira de se conduzir, as formas por meio das quais o sujeito se problematiza e concebe a sua ação são efeitos apenas na medida em que são também causas eficientes de assujeitamento - este último devendo ser entendido não no sentido negativo da obediência a uma norma, mas naquele, positivo, de um certo posicionamento dos indivíduos pelo qual eles próprios se constituem como sujeitos. Assim, a propósito da maneira pela qual a atividade sexual é problematizada na Grécia antiga: "É necessário compreender estes temas de austeridade sexual não como uma tradução ou um comentário

4 Em português o substantivo "probabilidade" não possui um verbo correlato, a não ser "poder", de modo que essa expressão pode ser traduzida na frase acima como "prevê", já que probabilidade é definido como “qualidade do que pode vir a acontecer". No entanto, como previsão pode suscitar outras possibilidades semânticas, demos preferência a um neologismo que entendemos guardar sua relação mais próxima com probabilidade. (NT).

5 "Tournant(e)" pode ser traduzido também como "giratório", "que contorna, que cerca", "movimento importante de mudança", "momento decisivo", "curva". (NT). 
de proibições profundas e essenciais, mas como elaboração e estilização de uma atividade no exercício do seu poder e na prática de sua liberdade"10. O que significa, afinal de contas, a renúncia, no âmbito de análise do poder, à forma geral da dominação e ao sujeito obediente que é o seu corolário imediato é precisamente que o assujeitamento é, nele mesmo, um processo afirmativo de subjetivação, e deve, por esta razão, ser considerado a partir das práticas subjetivas que põe em jogo.

$* * *$

É preciso ter a medida exata, se não da distância insuperável que separa Foucault das concepções marxistas, ao menos da injunção que se encontra, a partir daí, lançada a qualquer empreendimento neomarxista, de redefinir seus princípios teóricos acerca da questão crucial da alienação. Pois, nas condições definidas por uma concepção positiva do poder, deve-se falar menos de uma alienação ou de uma submissão efetiva do que de um certo regime em que submissão e insubmissão convivem e sustentam-se segundo mecanismos complexos, desenhando, assim, o espaço diferenciado e, contudo, coerente de toda experiência subjetiva. Ora, nesta perspectiva, o fato de as resistências subsistirem no centro do poder certamente não resulta de um laxismo constituinte ou de uma incapacidade do poder de assegurar sua completa hegemonia. Não somente resistências e insubmissões não têm nada de contingente e de acidental como sua necessidade prolongase até constituí-los como componentes ativos daquilo a que parecem, à primeira vista, opor-se.

A consequência prática parece, então, imediata: reinserida no dispositivo de poder no interior do qual assume seu verdadeiro significado, a luta perderia seu poder de contestação, correndo, assim, o risco de jogar, em definitivo, contra si mesma. Conclusão, em resumo, bastante decepcionante: ter-se-ia apenas descoberto, por um longuíssimo desvio, o tema suficientemente repetido da recuperação, lugar comum da construção das lutas no campo social. Mas não se trata disso: pois pensar em termos de recuperação, ou seja, segundo uma lógica a posteriori que dispõe o poder por detrás dos fenômenos de resistência e concebe sua ação sobre estes últimos pelo modo do desvio ou da inversão, contradiz diretamente a concepção positiva que nos temos esforçado em caracterizar. Dito isto, em uma abordagem que rejeita toda forma de transcendência do poder em relação ao seu objeto, a questão da vigilância ganha, certamente, uma acuidade ainda maior. E podemos ainda melhor duvidar da eficácia real de qualquer forma de resistência a partir 
do momento em que se admite que o poder não é precisamente outra coisa senão a multiplicidade concreta das lutas, formalizada e mantida num certo estado de equilíbrio por um processo de interação e de estabilização interna.

Porém, quando nos dedicamos a definir esse estado de equilíbrio, o termo estabilização revela-se muito rapidamente impróprio. Porque, no contexto de uma compreensão rigorosamente imanente, é claro que se deve renunciar a conceber o exercício do poder sob a forma de uma anulação das lutas, a do projeto reformista ou conservador de reduzi-las ao silêncio e de impedir sua emergência. Ao contrário, é a partir das lutas, no plano mesmo onde elas se desdobram e entram em relação umas com os outras, que se opera a antecipação que é característica do poder considerado como tipo específico de gestão e de distribuição dos fluxos. Nesse sentido, o equilíbrio do dispositivo de poder repousa bem mais sobre uma instabilidade regulada do que sobre uma verdadeira estabilidade. Mais precisamente, a estabilização é sempre adiada ${ }^{6}$, situando-se frequentemente à frente dele, relançada como desafio permanente ao qual é confrontado em virtude de sua própria natureza de dispositivo. A produção de sua unidade, sua individuação como dispositivo não pode, a este respeito, ser concebida na modalidade de fechamento. Falar de dispositivo, e não de sistema, demonstra, em Foucault, a intenção bastante precisa de expressar o modo de totalização específico que corresponde à efetivação do poder e sua irredutibilidade diante de outros modos de totalização.

Se o dispositivo não é um sistema, não é somente porque não comporta um princípio de fechamento, mas também porque sua coerência não é interna. Repousa sobre o novo confronto, que o conecta ao seu exterior; sobre sua capacidade, incessantemente posta à prova, de modificar o tipo de estruturação que opera de modo a integrar e a governar as possibilidades inéditas que se atualizam seja sob a forma de fenômenos de submissão ou de fenômenos de resistência. Ao lado do equilíbrio estável do sistema, há o equilíbrio metaestável do dispositivo, que compõe, de maneira completamente inédita, as dimensões classicamente opostas do um e do múltiplo, do ser e do 'vir a ser': isso porque a unidade do dispositivo só pode ser concebida dinamicamente, como uma

6 Nesse contexto, entendemos que o termo "différée" (como está no texto original) pode ser traduzido como "adiada" ou "diferida". (NT) 
unidade que acontece ${ }^{7}$ e no seio da qual a multiplicidade das práticas subjetivas não é nem dissolvida nem neutralizada. Dessa multiplicidade, não seria necessário sequer dizer que permanece, no sentido de uma certa entidade residual; mas que ela insiste, produzindo, por si própria e nela mesma, seu próprio modo de formalização.

É à luz desta caracterização de dispositivo que se antevê o que pode ser o horizonte paradoxal de uma autêntica construção de lutas. Horizonte, de fato, eminentemente paradoxal, já que resulta da própria natureza do poder considerado como dispositivo metaestável, conjunto complexo e dinâmico no qual se pode identificar pontualmente focos de resistência, descrever e compreender sua especificidade e, a partir desta abordagem local, tentar decifrar suas correlações estratégicas. Dessa leitura e dessa decodificação nasce, então, um pequeno descompasso no qual pode se insinuar a verdadeira contestação, a possibilidade de uma reviravolta do poder, e a constituição de saberes revolucionários que não procedem de um pensamento de "sobrevoo", mas se elaboram minuciosamente na experiência plural e diferenciada das massas: "Pois, se é verdade que no coração das relações de poder, e como condição permanente de sua existência, há uma "insubmissão" e liberdades essencialmente relutantes, não há relação de poder sem resistência, sem escapatória ou fuga, sem reviravolta eventual; toda relação de poder implica, então, ao menos de modo virtual, uma estratégia de luta sem que, para tanto, elas venham a se sobrepor, a perder a sua especificidade e, finalmente, a se confundir. Elas constituem uma para a outra uma espécie de limite permanente, um ponto de subversão possível "11.

A estreita correlação entre poder e luta não implica uma confusão dos planos. Pode-se bem descrever sua relação como imanente, o que não permite que se afirme sua comensurabilidade plena, tampouco a assimilação pura e simples de um pelo outro. Pelo contrário, se as especificidades se conservam, é que a estratégia de poder não dissolve nela a elaboração de uma verdadeira estratégia de luta, mas forma sobretudo o percurso que esta última tem por finalidade permanente contrariar: no duplo sentido do termo, ela

7 No sentido de irrupção; como acontecimento. (NT). 
é, portanto, o seu limite. Ora, é justamente no coração dessa disjunção, traçada na imanência, que se inscrevem as difíceis condições de um empreendimento de debilitação do poder. Trata-se de desarranjar a metaestabilidade do dispositivo, apoiando-se precisamente sobre suas características fundamentais; de articular diferentes práticas de modo a não somente conservar as potências de contestação que se expressam com vigor e eficácia em nível local, mas, sobretudo, de modo a intensificá-las, estabelecendo, a partir de um foco de resistência identificado com precisão, ressonâncias com outras lutas. As estratégias de luta adquirem, desse ponto de vista, sua própria coerência: construir elos originais entre uma multiplicidade dispersa de pontos, isto é, afinal, organizar taticamente redes de instabilidades que retiram sua força global do fato de que não extinguem as singularidades que as compõem, mas avançam literalmente a partir delas.

$* * *$

Pode-se considerar que essa problematização do político diz respeito a preocupações datadas, inscritas numa espécie de habitus dos anos 70, e das quais nossa atualidade, por si só, suficientemente rica e nova, nos descentra um pouco mais a cada dia. Mas o que nos surpreende no seio dessa atualidade não é precisamente, em vez do puro e simples desaparecimento dessas questões, a violência inesperada pela qual somos a elas reconduzidos? O que os noticiários designam como característica dos "movimentos sociais", a permanência e a diversidade das contestações, a maneira como elas se sobrepõem e se entrelaçam sem jamais alcançar uma totalização nem desenhar uma categoria que as subsumiria, e, em seguida, como resultado disso, o fracasso repetido de toda forma de retomada política que opera com um aparelho categorial, unificando tudo isso, não nos atrai a prosseguir e a reinventar, à margem da ortodoxia marxista, um esquerdismo cujos esquemas teóricos talvez nunca tenham sido tão insistentes?

Já que no próprio interior das estratégias de poder enraíza-se um projeto que é necessário definir, em suma, como político, é preciso ouvir, continuar a ouvir e fazer ouvir aquilo que Foucault chamava de "o ronco surdo da batalha"12. 
Tradutoras e Supervisão

Sandra Raquel Santos de Oliveira
Professora Adjunta do Departamento de Psicologia da UFS
E-mail: sraquel.oliveira31@gmail.com

Larissa de Moura Cavalcante Mestranda do Programa de Pós-Graduação em Psicologia-UFS

Maria Cândida Santos e Moura Mestre em Estudos da Linguagem pelo Programa de Pós-Graduação em Letras - UFOP E-mail: mariacandidamoura@yahoo.com.br

Manoel Carlos Cavalcanti de Mendonça Filho Professor titular do Departamento de Psicologia da UFS E-mail:mmendoncafilho@gmail.com

${ }^{1}$ Ver "Os jogos de poder". In: Politicas da Filosofia, Grasset, 1976.

${ }^{2}$ Ver R. Rochlitz, "Estética da existência; moralidade pós-convencional e teoria do poder em Foucault". In: Michel Foucault, Philosophie, Seuil, 1990.

${ }^{3}$ Ver $O$ uso dos prazeres, p. 13.

4 "Dois ensaios sobre o sujeito e o poder", In: Dreyfus e Rabinow Michel Foucault, uma trajetória filosófica, p. 308.

${ }^{5}$ Ver A vontade de saber, p. 113.

${ }^{6}$ Ver, a respeito, Deleuze. Foucault, p. 37.

${ }^{7}$ A vontade de saber, p. 66-67.

${ }^{8}$ Ibid., p. 112.

${ }^{9}$ Dois ensaios sobre o sujeito e o poder, p. 314.

${ }^{10} \mathrm{O}$ uso dos prazeres, p. 30.

${ }^{11}$ Dois ensaios sobre o sujeito e o poder, p. 319.

${ }^{12}$ Vigiar e punir, p. 315. 